\title{
Effects of Temperature and Wetness Duration on Infection of Peanut Cultivars by Cercospora arachidicola
}

\author{
Lijun Wu, J. P. Damicone, J. A. Duthie, and H. A. Melouk
}

First, second, and third authors: Department of Entomology and Plant Pathology; and fourth author: USDA/ARS, Oklahoma State University, Stillwater 74078 .

Accepted for publication 23 April 1999.

\begin{abstract}
Wu, L., Damicone, J. P., Duthie, J. A., and Melouk, H. A. 1999. Effects of temperature and wetness duration on infection of peanut cultivars by Cercospora arachidicola. Phytopathology 89:653-659.

The effects of temperature and duration of wetness (relative humidity $\geq 95 \%$ ) on infection of three peanut cultivars by Cercospora arachidicola were determined under controlled conditions. Plants of the Spanish cv. Spanco and the runner cvs. Florunner and Okrun were exposed to constant temperatures of 18 to $30^{\circ} \mathrm{C}$ during 12 -h periods of wetness each day that totaled 12 to $84 \mathrm{~h}$ following inoculation of leaves with conidia. Severity of disease, measured by either lesion density (number per leaf) or lesion size (diameter), was greatest for 'Spanco', intermediate for 'Florunner', and lowest for 'Okrun' in each of two experiments. Lesion density was evaluated further because it was an indicator of both the occurrence and degree of infection. Nonlinear regression analysis was employed to evaluate the combined effects of temperature $(T)$ and wetness duration $(W)$ on lesion density $(Y)$. In the regression model, the Weibull function characterized the monotonic increase of $Y$ with respect to $W$, while a hyperbolic function characterized the unimodal response of $Y$ with respect

and the upper limit $(e)$ when $T$ is optimum $(T=g)$ were estimated for each cultivar and experiment. The effect of cultivar was characterized primarily by differences in the upper limit parameter $e$. In each experiment, $e$ was greatest for 'Spanco', intermediate for 'Florunner', and least for 'Okrun'. The effect of cultivar on $b$ followed a pattern similar to that for $e$ in experiment 1 , but not in experiment 2. Differences among cultivars for estimates of $f$ and $g$ were small and inconsistent. Estimates for $g$ were precise for each cultivar and experiment and fell within the range of 22.3 to $23.2^{\circ} \mathrm{C}$. Cultivar responses to $T$ and $W$ were further evaluated using data pooled over the two experiments. Parameter $e$ was estimated for each cultivar, but common values of $b, f$, and $g$ were estimated. At $e=22.8^{\circ} \mathrm{C}$, lesion density approached an upper limit of 96,17 , and 6 lesions per leaf for the cvs. Spanco, Florunner, and Okrun, respectively. These fitted values approximated the observed values of 86,25 , and 9 lesions per leaf for the respective cultivars. Cultivars varied in their response to $W$ at a given $T$. At $22.8^{\circ} \mathrm{C}$, one lesion per leaf was expected following 26,30 , and $36 \mathrm{~h}$ of wetness for 'Spanco', 'Florunner', and 'Okrun', respectively. If temperature was increased to $28^{\circ} \mathrm{C}$, one lesion per leaf was expected following 36,44 , and $54 \mathrm{~h}$ of wetness for the respective cultivars.
\end{abstract} to $T$. Parameters for the intrinsic rate of change with respect to $W(b)$, the intrinsic rate of change with respect to $T(f)$, the optimal value of $T(g)$,
Additional keywords: Arachis hypogaea, early leaf spot, groundnut.
Leaf spots caused by the fungi Cercospora arachidicola S. Hori and Cercosporidium personatum (Berk. \& M.A. Curtis) Deighton are the most important foliar diseases of peanut (Arachis hypogaea L.) worldwide. In Oklahoma and the Virginia/Carolina production region, early leaf spot $(C$. arachidicola) has been the most prevalent and damaging foliar disease $(7,10,11)$. Yield losses near $50 \%$ may result from failure to control early leaf spot $(11,42)$. In the United States, the disease is managed primarily with fungicide spray programs, although crop rotation and residue management programs may also reduce disease. Some partially resistant cultivars are available; however, the level of resistance has not been sufficient to offset the need for a fungicide program $(25,26)$.

Outbreaks of early leaf spot are dependent on weather, and the effects of temperature and wetness have been studied extensively. Jensen and Boyle (23) observed an association between disease increase in the field and the duration of relative humidity $(\mathrm{RH}) \geq 95 \%$, hereafter referred to as wetness duration. A nomogram depicting the interacting effects of wetness duration and the minimum temperature during the wet period was developed to forecast the increase in disease (24). The nomogram was adapted to schedule fungicide sprays by Parvin et al. (37) (hereafter referred to as PSC).

Corresponding author: J. P. Damicone; E-mail address: jpd3898@okstate.edu

Publication no. P-1999-0614-01R

This article is in the public domain and not copyrightable. It may be freely reprinted with customary crediting of the source. The American Phytopathological Society, 1999.
The PSC advisory program has been modified and employed to increase the efficiency of disease control with fungicides $(7,38)$.

The effects of temperature and wetness on infection processes for C. arachidicola have been studied in more depth since Jensen and Boyle's work (23). Oso (34) and Alderman and Beute (2) reported that conidia require a saturated or near-saturated atmosphere to germinate at optimum temperatures of 16 to $25^{\circ} \mathrm{C}$. Germ tubes elongated at a RH as low as $94.5 \%$ and were able to withstand intermittent dry periods and resume elongation when moisture became available again (2). Germ tubes elongated for up to 12 days before penetrating leaves through stomata $(1,2)$. These results suggest that infection may occur following the accumulation of interrupted periods of wetness over a prolonged period. However, the combined effects of temperature and the duration of continuous or interrupted periods of wetness on the development of early leaf spot under controlled conditions has never been quantified.

$\mathrm{Cu}$ and Phipps (10) developed an advisory program in Virginia (VA program) based on pathogen sporulation (3), conidial germination (34), and germ tube elongation $(1,2)$ in response to weather. The VA program accumulates continuous or interrupted periods of favorable temperature $\left(16\right.$ to $\left.32^{\circ} \mathrm{C}\right)$ and $\mathrm{RH}(\geq 95 \%)$. Infection is predicted and a spray recommended when a favorable period totals $48 \mathrm{~h}$ (10). Adjustments in the cumulative total (threshold) were proposed for cultivars that differ in reaction to early leaf spot (10).

While complete resistance to early leaf spot has not been identified in Arachis spp. $(1,26)$, various levels of partial resistance have been observed and quantified in several peanut genotypes $(1,20,21$, 29,30,39,43-45). Components of partial resistance include reduced 
number of lesions or necrotic area per leaf $(1,20,21,29,43,44)$, reduced lesion diameter $(1,44)$, increased incubation period $(44)$, increased latent period $(26,33,39)$, reduced sporulation $(1,20,26,33$, $39,44)$, and increased time to defoliation $(26,39)$. The components of resistance are often interrelated $(36,39,44)$ and lead to reduced rates of disease development and area under the disease progress curve (AUDPC) $(26,36)$. Most of the partially resistant genotypes evaluated have been breeding lines identified or developed for cultivar improvement. However, the Virginia-type cvs. NC 5 (25, $28)$ and NC $6(28,45)$ have partial resistance to early leaf spot.

In evaluating a modified PSC advisory program (7) in Oklahoma, the runner cvs. Okrun and Florunner expressed a delay in leaf spot increase and reduced AUDPC compared with the Spanish cv. Spanco (11). Similar differences between the Spanish and runner cultivars were observed in evaluating the VA advisory program (47). In addition, the most efficient threshold was greater for the runner than for the Spanish cultivars (47), suggesting a differential response of cultivars to wetness duration and temperature, either alone or together.

The combined effects of temperature and wetness duration on a variety of diseases have been described by polynomial equations comprising numerous parameters that lacked a clear epidemiologic significance $(4-6,16,17,19,31)$. Duthie (13) recently described a nonlinear model for evaluating the combined effects of temperature and wetness duration. While parameters of this model can be interpreted to provide information on the mechanisms involved in the disease response, reports on fitting empirical data and interpreting the response have not been published. The objectives of this study were to develop nonlinear models to (i) quantify the temperature and wetness requirements for infection of some runner and Spanish cultivars by $C$. arachidicola under controlled conditions; (ii) characterize the cultivar responses to temperature and wetness duration for certain components of infection; and (iii) elucidate mechanisms by which infection is influenced by cultivar, temperature, and wetness duration. Brief reports of this study were published previously $(14,15)$.

\section{MATERIALS AND METHODS}

Seeds of the Spanish cv. Spanco and the runner cvs. Florunner and Okrun were planted into 12-cm-diameter plastic cups containing sand, soil, and peat moss in a 2:1:1 ( $\mathrm{vol} / \mathrm{vol} / \mathrm{vol})$ mixture and were thinned to one plant per pot. Prior to inoculation, plants were grown in the greenhouse at 20 to $30^{\circ} \mathrm{C}$ for 40 to 60 days until the R2 (beginning peg) stage of development (8). Pots were drenched with Hoagland's nutrient solution (12) at about 2 and 4 weeks after emergence.

TABLE 1 . Severity of early leaf $\operatorname{spot}^{\mathrm{w}}$ on three peanut cultivars inoculated with Cercospora arachidicola in each of two controlled-environment experiments

\begin{tabular}{|c|c|c|c|c|c|}
\hline \multirow[b]{2}{*}{ Experiment } & \multirow[b]{2}{*}{ Cultivar } & \multicolumn{2}{|c|}{ Lesion density (no./leaf) } & \multicolumn{2}{|c|}{ Lesion $\operatorname{size}^{\mathrm{x}}(\mathrm{mm})$} \\
\hline & & Mean & $\begin{array}{c}\text { No. of } \\
\text { observations }^{y}\end{array}$ & Mean & $\begin{array}{c}\text { No. of } \\
\text { observations }\end{array}$ \\
\hline \multirow[t]{4}{*}{1} & Spanco & 16.1 & 28 & 1.7 & 26 \\
\hline & Florunner & 5.7 & 29 & 1.5 & 26 \\
\hline & Okrun & 2.4 & 30 & 1.1 & 24 \\
\hline & Mean & 7.9 & 87 & 1.5 & 76 \\
\hline \multirow[t]{4}{*}{2} & Spanco & 16.1 & 27 & 1.6 & 23 \\
\hline & Florunner & 4.1 & 27 & 1.5 & 19 \\
\hline & Okrun & 1.7 & 29 & 1.3 & 21 \\
\hline & Mean & 7.2 & 83 & 1.5 & 63 \\
\hline
\end{tabular}

${ }^{\text {w Values are means over five temperatures, six durations of high relative }}$ humidity, three plants, and two inoculated leaves per plant.

${ }^{x}$ Diameter of the three largest lesions per leaf; leaves without lesions were treated as missing values.

y Ten outlying observations were omitted.

${ }^{\mathrm{z}}$ Forty-one observations were missing as either outliers $(N=10)$ or without lesions $(N=31)$.
Four single-conidial isolates of $C$. arachidicola from various peanut production areas in Oklahoma were compared in a preliminary infectivity assay and were equally virulent. One isolate was selected for the remaining experiments and stored on silica gel at $4^{\circ} \mathrm{C}(12)$. For each inoculation, the isolate was cultured from storage stock on potato carrot agar (12) acidified to $\mathrm{pH} 5.5$ with lactic acid. Sporulation was induced by maintaining cultures under a 14-h photoperiod of 800 -lux fluorescent light at $25^{\circ} \mathrm{C}$ for 10 to 12 days. Conidial suspensions were prepared by flooding the cultures with sterile distilled water containing Amway surfactant (Amway Corporation, Ada, MI) at two drops per $100 \mathrm{ml}$ and filtering through cheesecloth. Suspensions were adjusted to $4 \times 10^{4}$ conidia per $\mathrm{ml}$ with a hemacytometer.

The second and third youngest, fully expanded leaves of each plant were inoculated using a modification of a procedure described by Evans et al. (18). Briefly, a clear plastic cylinder, 20-cm long by $5-\mathrm{cm}$ inside diameter, was attached vertically to a ring stand. A DeVilbiss No. 152 atomizer (DeVilbiss Co., Somerset, PA) was attached to the top of the cylinder. Inoculum was delivered to leaves or glass slides held against the lower orifice with a plastic inoculation stage. Inoculation times were regulated by a timer attached to the atomizer pump. The upper surface of each peanut leaf was inoculated for $5 \mathrm{~s}$.

Inoculum deposition was determined by inoculating glass slides and counting conidia in a $1-\mathrm{cm}^{2}$ area using a microscope. This was repeated 30 times while placing the glass slides in various positions within the outlet of the cylinder. The entire calibration procedure was repeated three times. Inoculum density was estimated as the mean number of conidia per square centimeter collected on the glass slides.

The mean leaf area of the second and third youngest leaves for each cultivar was determined with a video-imaging area meter (Delta-T Devices, Ltd., Cambridge, England). Three replications of 30 leaves per cultivar, produced in the same manner as those to be inoculated, were imaged. For each cultivar, the number of conidia deposited onto each leaf $\left(2.5\right.$ to $\left.3.5 \times 10^{3}\right)$ was estimated as the product of the mean number of conidia deposited per unit area and the mean leaf area.

Treatments were arranged in a split-split-plot design with temperature as the whole-plot treatment, cultivar the split-plot treatment, and duration of wetness $(\mathrm{RH} \geq 95 \%)$ as the split-split-plot treatment. There were three replicate plants with two inoculated leaves per plant for each combination of temperature and wetness.

Plants were exposed to various temperatures and wetness durations using two dew chambers. The order of temperature treatments was assigned at random. Within each temperature treatment of 18 , $21,24,27$, and $30^{\circ} \mathrm{C}$, plants were exposed to cumulative wetness periods of $0,12,24,36,48,60,72$, and $84 \mathrm{~h}$ in increments of $12 \mathrm{~h}$ per day. For each temperature, a wet chamber was set for a 12 -h night period of $\mathrm{RH} \geq 95 \%$ and a 12-h day period of a $\mathrm{RH}$ of 70 to $85 \%$. A dry chamber was set for a $24-\mathrm{h}$ period of a $\mathrm{RH}$ of 70 to $85 \%$ with a 12-h day and night cycle. Chambers were calibrated and monitored with a 7-day recording hygrothermograph (model 5020-A; Weathertronics, Sacramento, CA). Plants were inoculated at 1,600 to $1,800 \mathrm{~h}$ and placed in the wet chamber in three blocks. After exposure to the specified periods of $\mathrm{RH} \geq 95 \%$, a plant of each cultivar was randomly selected from each block and transferred to the dry chamber where they again were assigned to the three blocks.

Inoculated leaves were removed 30 days after inoculation. The number of lesions per leaf was counted, and lesion size was determined by measuring the diameter of the three largest lesions per leaf (41). The mean number of lesions per leaf (lesion density) and lesion size were calculated for each plant and the experiment was repeated.

Means for each response variable were taken over the three plants for each experiment, and experiments were treated as blocks. Effects of cultivar $(C)$, wetness duration $(W)$, and temperature $(T)$ on lesion density $(Y)$ and size were compared among experiments $(B)$ by analysis of variance (PROC GLM, Statistical Analysis System version 
6.11; SAS Institute, Cary, NC). For each response variable, heteroscedasticity was evaluated by inspecting standardized residual errors plotted against $W$ or $T$. Lesion density was transformed by $Y^{\prime}=$ $\ln (Y+1)$ to minimize heteroscedasticity.

The differential response of cultivars to the combined effects of temperature and wetness duration for lesion density was further evaluated by a nonlinear equation of the form

$$
Y^{\prime}=f(W, T)=a\left(1-\exp \left\{-[b(W-c)]^{d}\right\}\right)
$$

in which $a$ varies with temperature according to

$$
a=f(T)=e^{\prime}\{\exp [f(T-g) /(h+1)]\} /\{1+\exp [f(T-g)]\}
$$

(13). In each equation, italicized upper case letters represent variables and italicized lower case letters represent parameters, unless specified otherwise. Briefly, equation 1 is a Weibull function (27) that describes the monotonic increase of $Y^{\prime}$ with respect to $W$ from a minimum of $Y^{\prime}=0$ at $W=c$ to a temperature-dependent upper limit of $a$ when $W$ is large. Thus, $c(0<c<+\infty)$ characterizes the lag period before the response of $Y^{\prime}$ to $W$ begins and $a(0<a<$ $+\infty)$ characterizes the scale of the response to $W$. The parameters $b(0<b<1)$ and $d(0<d<1)$ characterize the intrinsic rate of increase of $Y^{\prime}$ with respect to $W$ and the intrinsic rate of acceleration, respectively. Equation 2 describes the unimodal response of $a$ to $T$ at each $W$. The value of $e^{\prime}$ is given by

$$
e^{\prime}=e\left\{[(h+1) / h] h^{1 /(h+1)}\right\}
$$

in which $e$ characterizes the scale of the response to $T$. The parameters $f(0<f<1)$ and $g(-\infty<g<+\infty)$ characterize the intrinsic rate of change of $Y^{\prime}$ with respect to $T$ and the optimal temperature, respectively. At $T=g, Y^{\prime}$ approaches an upper limit of $e$ when $W$ is large. As $T$ deviates from $g$ at each $W, Y^{\prime}$ declines at an intrinsic rate of $f$ toward a lower limit of 0 . The parameter $h$ characterizes asymmetry in the response to $T$.

Nonlinear models were fitted to data by an iterative, derivativefree, nonlinear, least squares, regression procedure (PROC NLIN, Statistical Analysis System version 6.11; SAS Institute). Goodnessof-fit was evaluated by the magnitude of asymptotic confidence intervals on parameter estimates and by inspection of observed values and predicted values plotted simultaneously against $W$ or $T$. Heteroscedasticity was evaluated by inspecting standardized residual errors plotted against predicted values. Overparameterization was assessed by the magnitudes of asymptotic standard errors and asymptotic correlation coefficients.

In a preliminary regression analysis, equation 1 was fitted to data for each cultivar in each experiment separately. The model clearly was overparameterized, and the iterative regression procedure failed to converge on a solution. The model was reduced by fixing the parameters $c, d$, and $h$ to values of $0,3.3$, and 1 , respectively. These parameter values implied the following simplifying assumptions: (i) $Y^{\prime}$ responded immediately to $W$ following the start of the wetness period, (ii) the response of $Y^{\prime}$ to $W$ was sigmoidal and approximately symmetrical about the point of inflection $(22,27)$, and (iii) the response of $Y^{\prime}$ to $T$ was symmetrical about the optimum temperature, respectively. The parameters $c, c$ and $d$, and $c, d$, and $h$ were fixed in a six-parameter, five-parameter, and four-parameter form, respectively, of equation 1. The four-parameter equation

$$
Y^{\prime}=f(W, T)=e\left\{1-\exp \left[-(b W)^{3.3}\right]\right\} / \cosh [f(T-g)]
$$

adequately described the response for each cultivar, but was not overparameterized. The response to $T$ described by equation 2 was simplified to the hyperbolic cosine function

$$
1 / \cosh [f(T-g)]=2 e /\{\exp [-f(T-g)]+\exp [f(T-g)]\}
$$

in equation 4.

Variation in effects of wetness duration and temperature among cultivars, on average over the two experiments, was evaluated for- mally by a modified form of equation 3 in which $e$, but not $b, f$, or $g$, was cultivar dependent. The structure of the model was based on the results of the preliminary regression analysis and the analysis of variance. For example, analysis of the response on average over the two experiments was justified by the small variation among experiments in the effects of the treatment factors in the analysis of variance and by similarity of the effects of the treatment factors in the preliminary regression analysis (discussed below). The large difference among cultivars in the estimate of $e$ (discussed below) supported the simplifying assumption that $e$, but not $b, f$, or $g$, was cultivar dependent. In the modified equation, the independent variables $V_{\mathrm{s}}, V_{\mathrm{f}}$, and $V_{\mathrm{o}}$ together specified the cultivar. For an observation of the cvs. Spanco, Florunner, or Okrun, $V_{\mathrm{s}}, V_{\mathrm{f}}$, or $V_{\mathrm{o}}$, respectively, a value of 1 was assigned. Otherwise, the value of $V_{\mathrm{s}}$, $V_{\mathrm{f}}$, or $V_{\mathrm{o}}$ was 0 . The parameter $e$ was then described by a linear function of the form

$$
e=e_{\mathrm{s}} V_{\mathrm{s}}+e_{\mathrm{f}} V_{\mathrm{f}}+e_{\mathrm{o}} V_{\mathrm{o}}
$$

and the parameters $e_{\mathrm{s}}, e_{\mathrm{f}}$, and $e_{\mathrm{o}}$ estimated distinct upper limits on $Y^{\prime}$ for the cvs. Spanco, Florunner, and Okrun, respectively.

\section{RESULTS}

Leaf spot did not develop at any temperature for the three cultivars following exposure to 0 and $12 \mathrm{~h}$ of wetness. Therefore, these data were excluded from the analysis. For lesion density, 10 outlying observations were considered anomalous and, therefore, were treated as missing values. For lesion size, observations without lesions also were treated as missing. This was done to ensure that lesion size was independent of lesion density.

Severity of disease, measured by lesion density and lesion size averaged over all temperatures and wetness durations, was least for 'Okrun' and greatest for 'Spanco' in each experiment (Table 1). 'Florunner' was intermediate in disease severity. With respect to lesion density, the difference between 'Florunner' and 'Spanco' was

\begin{tabular}{|c|c|c|c|c|c|c|}
\hline \multirow[b]{2}{*}{ Source } & \multicolumn{3}{|c|}{ Lesion density ${ }^{\mathrm{v}}$ (no./leaf) } & \multicolumn{3}{|c|}{ Lesion size ${ }^{\mathrm{W}}(\mathrm{mm})$} \\
\hline & df & $\begin{array}{l}\text { Sum of } \\
\text { squares }\end{array}$ & $P>F^{\mathrm{x}}$ & df & $\begin{array}{l}\text { Sum of } \\
\text { squares }\end{array}$ & $P>F$ \\
\hline$B$ & 1 & 1.21 & ns & 1 & 0.11 & ns \\
\hline$T$ & 4 & 58.76 & $* *$ & 4 & 22.42 & $* *$ \\
\hline$T(B)-($ error a $)$ & 4 & 0.73 & ns & 4 & 0.07 & ns \\
\hline Whole-plot total & 9 & & & 9 & & \\
\hline$C$ & 2 & 43.83 & $* *$ & 2 & 7.16 & $* *$ \\
\hline$C \times T$ & 8 & 9.09 & ns & 8 & 1.95 & $\mathrm{~ns}$ \\
\hline$C \times T(B)-($ error b $)$ & 10 & 5.87 & $* *$ & 10 & 1.63 & ns \\
\hline Split-plot total & 20 & & & 20 & & \\
\hline$W$ & 5 & 76.13 & $* *$ & 5 & 8.83 & $* *$ \\
\hline$W \times T$ & 20 & 14.44 & $* *$ & 20 & 4.01 & ns \\
\hline$W \times C$ & 10 & 5.82 & $* *$ & 10 & 2.30 & ns \\
\hline$W \times C \times T$ & 40 & 5.12 & ns & 33 & 3.53 & ns \\
\hline$W \times C \times T(B)-($ error c $)$ & 65 & 13.55 & & 41 & 5.27 & \\
\hline Split-split-plot total & 140 & & & 109 & & \\
\hline Grand total & $169^{y}$ & & & $138^{\mathrm{z}}$ & & \\
\hline
\end{tabular}
greater than between 'Florunner' and 'Okrun'. The degree of the differences between cultivars was greater for lesion density than

TABLE 2. Analysis of variance ${ }^{\mathrm{u}}$ for the effects of experiment $(B)$, temperature $(T)$, cultivar $(C)$, and duration of high relative humidity $(W)$ on severity of early leaf spot of peanut

u Analysis of variance was performed on mean values for three plants with two inoculated leaves per plant $(n=180)$.

${ }^{v}$ Lesion density was transformed to $Y^{\prime}=\ln (Y+1)$.

${ }^{w}$ Diameter of the three largest lesions per leaf; observations without lesions were treated as missing values.

$\mathrm{x} * *=$ Significant at $P \leq 0.01$ and $\mathrm{ns}=$ not significant at $P \leq 0.05$.

y Ten outlying data points were omitted from the analysis.

${ }^{\mathrm{z}}$ Forty-one observations were missing as either outliers $(N=10)$ or without lesions $(N=31)$. 
for lesion size. In experiment 1, for example, 'Florunner' had $64 \%$ fewer lesions per leaf compared with 'Spanco', while lesion size for 'Florunner' was only $12 \%$ less than for 'Spanco'. Overall mean disease severities were similar for the first and second experiments.

In the analysis of variance, lesion density and lesion size were largely dependent on temperature, cultivar, and wetness duration (Table 2). Each of the main effects were significant $(P<0.01)$. In addition, lesion density was more responsive to interacting effects of treatments than lesion size. Significant $(P<0.01)$ variation in the response to wetness duration among temperatures and wetness duration among cultivars was detected for lesion density, but not lesion size. Except for the variation in temperature response of lesion density among cultivars within experiments (split-plot error), variation among experiments with respect to temperature, cultivar, and wetness duration was not significant $(P>0.05)$.

In the fitting of data to equation 4 by experiment and cultivar, plots of observed versus predicted values suggested that this form of equation 1 approximated the observed response for each cultivar. Estimates of asymptotic standard errors and asymptotic correlation coefficients were not large. Effects of wetness duration and temperature were similar in the two experiments. For each cultivar in each experiment, lesion density increased sigmoidally with increasing wetness duration. The response to temperature was unimodal, with lesion density greatest near the middle of the temperature range and least near the extreme temperatures. Results of the nonlinear regression analysis were consistent with the results of the analysis of variance. The large effects of wetness duration and temperature in the analysis of variance were reflected in the large estimates of the rate of increase with $W$ (parameter $b$ ) and the rate of change with $T$ (parameter $f$ ), respectively, in nonlinear regressions (Table 3 ).

Differences among cultivars were similar in the two experiments. Resistance was characterized primarily by differences in the upper limit of disease (parameter $e$ ). In each experiment, $e$ was greatest for 'Spanco', intermediate for 'Florunner', and least for 'Okrun' (Table 3). Effects of cultivar on the rate of change with respect to $W$ (parameter $b$ ) were less pronounced. In experiment $1, b$ was greatest for 'Spanco', intermediate for 'Florunner', and least for 'Okrun'. For experiment 2, $b$ again was greater for 'Spanco' than for 'Florunner', but was discrepantly large and imprecisely esti- mated for 'Okrun'. The rate of change with respect to $T$ (parameter $f$ ) was the least-precisely estimated parameter. Differences among cultivars in estimates of $f$ were inconsistent among experiments. In experiment $1, f$ was greater for 'Spanco' and 'Florunner' than for 'Okrun'. In experiment 2, $f$ did not differ among cultivars and was discrepantly high for 'Okrun'. The difference between experiments for values of $f$ was reflected by the significant variation in temperature response among cultivars within experiments in the analysis of variance (Table 2). There were no differences in the optimal value of $T$ (parameter $g$ ) among cultivars or experiments. For each cultivar in each experiment, $g$ was the most-precisely estimated parameter. Estimates of $g$ fell within the range of 22.3 to $23.2^{\circ} \mathrm{C}$

Cultivar responses to temperature and wetness duration over experiments were compared by the modified form of equation 4 in which $e$ was cultivar specific, and $b, f$, and $g$ were not (Table 4). The model was not overparameterized, all parameters were estimated precisely and asymptotic correlation coefficients were small. The parameter $e$ clearly characterized the effect of cultivar on lesion density. At the optimum temperature of $22.8^{\circ} \mathrm{C}$, lesion density approached an upper limit of 96, 17, and 6 lesions per leaf for the cvs. Spanco, Florunner, and Okrun, respectively (Fig. 1). The expected values approximated the observed values of 86,25 , and 9 lesions per leaf for 'Spanco', 'Florunner', and 'Okrun', respectively. Cultivars responded differently to wetness duration at a given temperature. At $22.8^{\circ} \mathrm{C}$, one lesion per leaf was expected following 26, 30, and $36 \mathrm{~h}$ of wetness for 'Spanco', 'Florunner', and 'Okrun', respectively. If temperature was increased to $28^{\circ} \mathrm{C}$, one lesion per leaf was expected following 36, 44, and $54 \mathrm{~h}$ of wetness for the respective cultivars.

\section{DISCUSSION}

The effects of temperature and cumulative periods of interrupted wetness on infection of three peanut cultivars by $C$. arachidicola was defined under controlled conditions. Differences in the disease reaction of the cultivars that were observed in previous field experiments were confirmed by mean lesion density and size averaged over various combinations of temperature and wetness duration. Analysis of variance demonstrated the large effects of tem-

TABLE 3. Parameter estimates for the model $Y^{\prime}=f(W, T)=e\left\{1-\exp \left[-(b W)^{3.3}\right]\right\} / \cosh [f(T-g)]^{\mathrm{x}}$ that characterized the effects of temperature $(T)$ and duration of wetness $(W)$ on density of leaf spots caused by Cercospora arachidicola for three peanut cultivars in each of two experiments

\begin{tabular}{|c|c|c|c|c|c|c|c|c|c|c|c|c|c|}
\hline \multirow[b]{2}{*}{ Cultivar } & \multirow[b]{2}{*}{ Experiment } & \multicolumn{3}{|c|}{$e\left(\times 10^{0}\right)^{\mathrm{y}}$} & \multicolumn{3}{|c|}{$b\left(\times 10^{2}\right)$} & \multicolumn{3}{|c|}{$f\left(\times 10^{1}\right)$} & \multicolumn{3}{|c|}{$g\left(\times 10^{-1}\right)$} \\
\hline & & Est. $^{\mathrm{z}}$ & $\mathrm{L}_{95}$ & $\mathrm{U}_{95}$ & Est. & $\mathrm{L}_{95}$ & $\mathrm{U}_{95}$ & Est. & $\mathrm{L}_{95}$ & $\mathrm{U}_{95}$ & Est. & $\mathrm{L}_{95}$ & $\mathrm{U}_{95}$ \\
\hline \multirow[t]{2}{*}{ Spanco } & 1 & 4.75 & 3.91 & 5.59 & 2.66 & 2.25 & 3.08 & 3.43 & 2.73 & 4.12 & 2.25 & 2.19 & 2.30 \\
\hline & 2 & 4.37 & 3.89 & 4.84 & 2.21 & 1.98 & 2.44 & 2.53 & 2.06 & 2.99 & 2.32 & 2.26 & 2.38 \\
\hline Florunner & 2 & 3.49 & 2.61 & 4.37 & 1.94 & 1.53 & 2.34 & 4.05 & 2.72 & 5.37 & 2.23 & 2.17 & 2.30 \\
\hline \multirow[t]{2}{*}{ Okrun } & 1 & 2.64 & 1.74 & 3.55 & 1.49 & 1.19 & 1.79 & 1.77 & 1.10 & 2.45 & 2.25 & 2.06 & 2.44 \\
\hline & 2 & 2.13 & 1.50 & 2.77 & 2.26 & 1.68 & 2.83 & 4.41 & 2.80 & 6.02 & 2.29 & 2.22 & 2.36 \\
\hline
\end{tabular}

x In this model, $Y^{\prime}=\ln (Y+1)$, in which $Y$ was the number of leaf spots per leaf and the parameters $e, b, f$, and $g$ were estimated from the data as described in text.

y Parameter estimates have been multiplied by values in parentheses.

${ }^{z}$ Est., $\mathrm{L}_{95}$, and $\mathrm{U}_{95}$ are the parameter estimate and the associated lower and upper $95 \%$ asymptotic confidence limits about the estimate, respectively.

TABLE 4. Parameter estimates for the model $Y^{\prime}=f(W, T)=e\left\{1-\exp \left[-(b W)^{3.3}\right]\right\} / \cosh [f(T-g)]^{\mathrm{x}}$ that characterized the effects of temperature $(T)$ and duration of wetness $(W)$ on density of leaf spots caused by Cercospora arachidicola for three peanut cultivars for pooled data from two experiments

\begin{tabular}{|c|c|c|c|c|c|c|c|c|c|c|c|c|}
\hline \multirow[b]{2}{*}{ Cultivar } & \multicolumn{3}{|c|}{$e\left(\times 10^{0}\right)^{\mathrm{y}}$} & \multicolumn{3}{|c|}{$b\left(\times 10^{2}\right)$} & \multicolumn{3}{|c|}{$f\left(\times 10^{1}\right)$} & \multicolumn{3}{|c|}{$g\left(\times 10^{-1}\right)$} \\
\hline & Est. $^{\mathrm{Z}}$ & $\mathrm{L}_{95}$ & $\mathrm{U}_{95}$ & Est. & $\mathrm{L}_{95}$ & $\mathrm{U}_{95}$ & Est. & $\mathrm{L}_{95}$ & $\mathrm{U}_{95}$ & Est. & $\mathrm{L}_{95}$ & $\mathrm{U}_{95}$ \\
\hline Spanco & 4.58 & 4.17 & 4.99 & 2.21 & 2.06 & 2.37 & 2.94 & 2.63 & 3.25 & 2.28 & 2.25 & 2.31 \\
\hline Florunner & 2.87 & 2.54 & 3.22 & & & & & & & & & \\
\hline
\end{tabular}

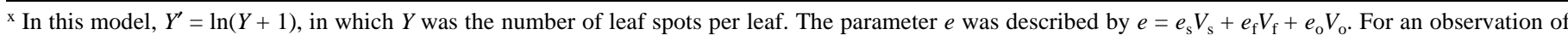
the cvs. Spanco, Florunner, or Okrun, $V_{\mathrm{s}}, V_{\mathrm{f}}$, or $V_{\mathrm{o}}$, respectively, had a value of 1 ; otherwise, the value of $V_{\mathrm{s}}$, $V_{\mathrm{f}}$, or $V_{\mathrm{o}}$, was 0 . The parameter $e$, but not the parameters $b, f$, and $g$, were assumed to be cultivar dependent as described in text.

y Parameter estimates have been multiplied by values in parentheses.

${ }^{\mathrm{z}}$ Est., $\mathrm{L}_{95}$, and $\mathrm{U}_{95}$ are the parameter estimate and the associated lower and upper $95 \%$ asymptotic confidence limits about the estimate, respectively. 
A

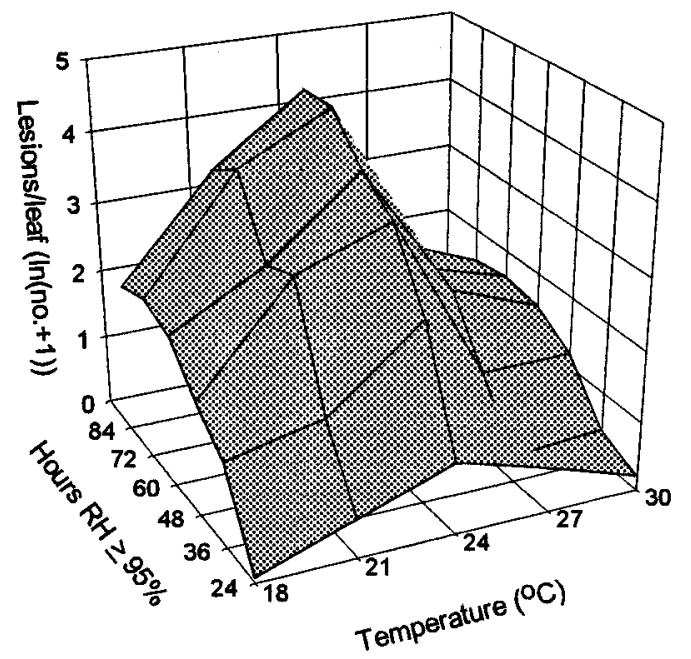

C

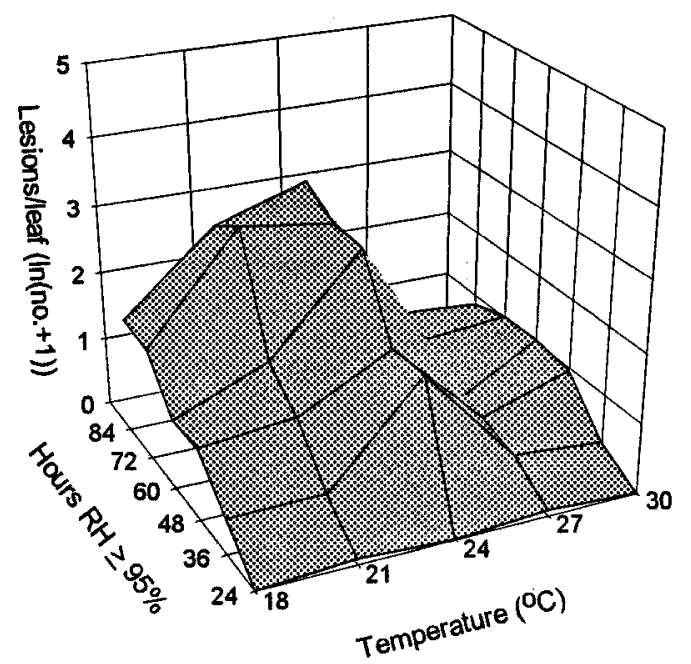

E

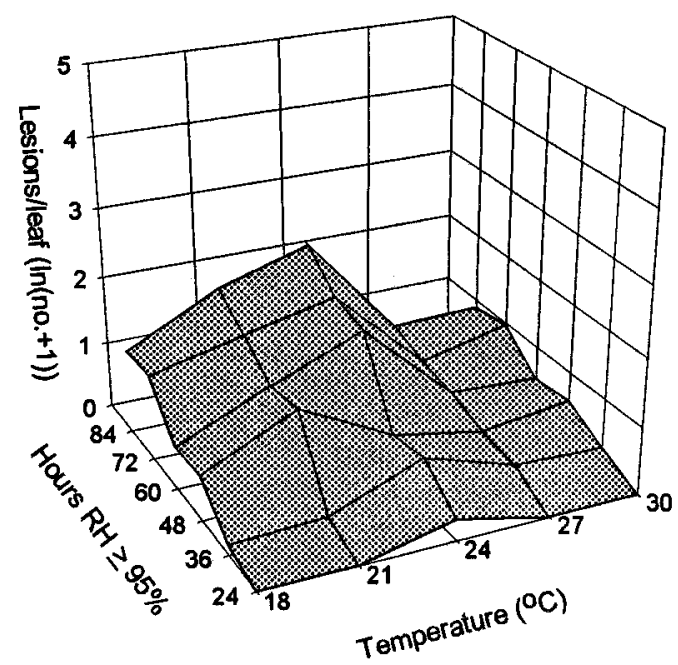

B

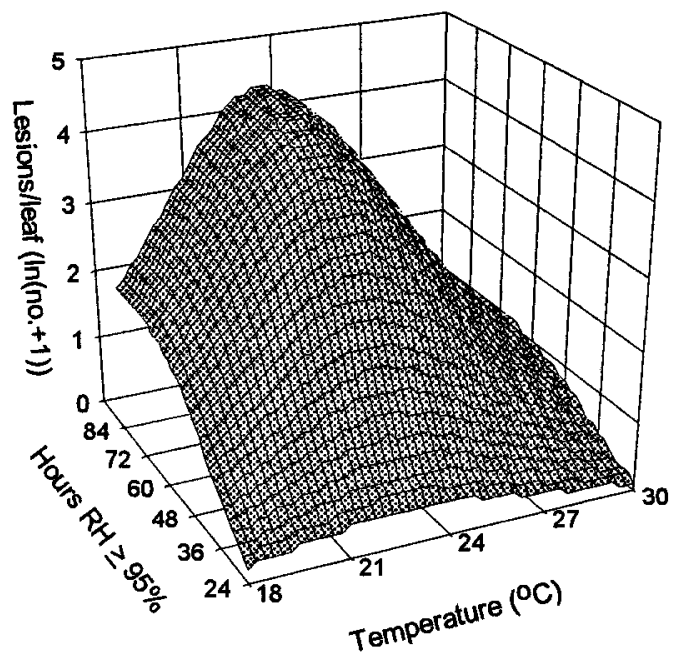

D

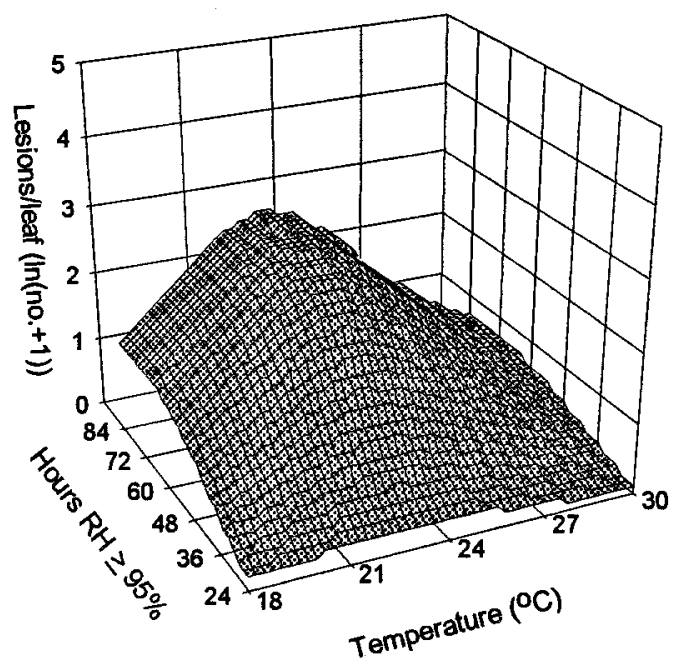

$\mathbf{F}$

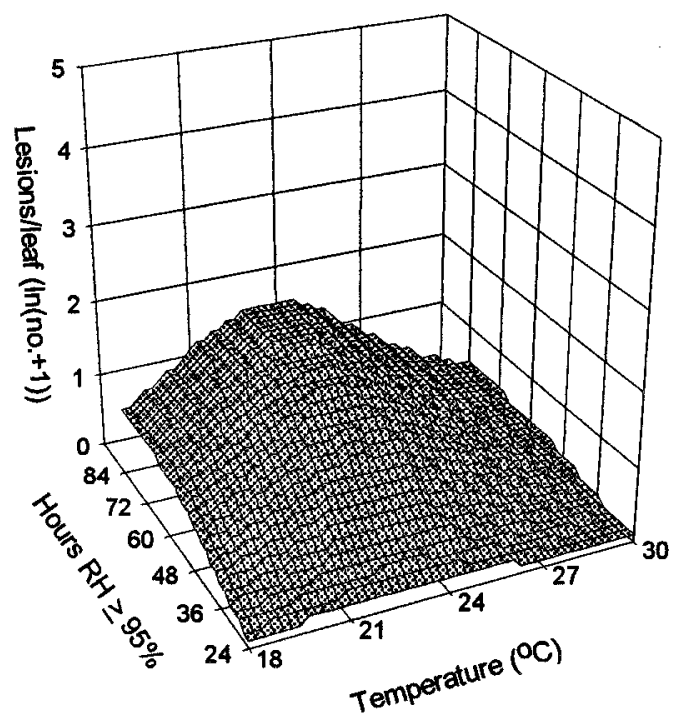

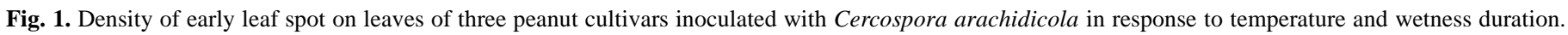

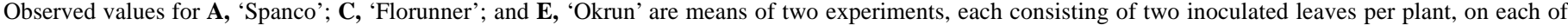

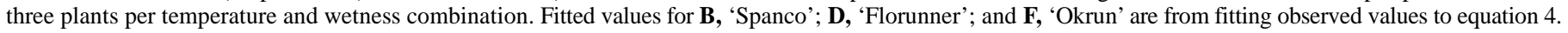


perature, cultivar, and wetness duration on lesion density and size. However, lesion density was chosen as a response variable for model development because it represented both the occurrence and degree of infection. For the first time, a nonlinear model was used to characterize a disease response to the combined effects of temperature and wetness duration. While data were not sufficient to estimate all parameters of equation 1, fixing some model parameters using simplifying assumptions permitted independent estimations of parameters for rates, upper limit, and temperature optima. Methods also were developed and demonstrated for characterizing the effects of cultivar resistance on the disease response in greater detail.

Many of the previous studies on the effects of temperature and wetness duration on the development of early leaf spot have focused on developing or improving weather-based advisory programs for disease management. In this study, attempts were made to verify differential cultivar responses to wetness duration that were observed in field trials, validating the VA advisory program in Oklahoma. The direct application of the detailed models developed in this study for disease forecasting is difficult. Equations could be used to predict temperature or cumulative wetness periods necessary for first infection (one lesion per leaf) for the specific cultivars. However, models do not account for temperature differences during the intermittent periods of wetness that occur in the field. Model outputs developed in this study might be better used as a framework for developing another simpler, rules-based forecaster or in improving existing advisory programs.

The response of lesion density to temperature was unimodal with an optimal temperature of $22.8^{\circ} \mathrm{C}$ for all cultivars. These results are similar to those of Alderman et al. (2), who found that elongation of germ tubes was optimum at $22^{\circ} \mathrm{C}$. Butler et al. (9) also reported a quadratic infection response to temperature for late leaf spot (Cercosporidium personatum). In this study, the decline in observed values of lesion density with increasing temperature from 24 to $30^{\circ} \mathrm{C}$ was not smooth and increased slightly at some wetness durations from 27 to $30^{\circ} \mathrm{C}$ for 'Florunner' and 'Okrun' (Fig. 1). As a result, predicted values at $27^{\circ} \mathrm{C}$ overestimated the observed response and estimates of parameter $f$ were imprecise, particularly for 'Florunner' and 'Okrun' in experiment 2. The overestimated response appeared to be a result of experimental error, as suggested by the significant split-plot error in the analysis of variance (Table 1). In the final model (Table 4), estimation of parameter $h$, the asymmetry in response to temperature, did not improve goodness-of-fit, and $h$ was highly correlated with parameter $e$ (data not shown). It may have been possible to better estimate $h$ with a more detailed data set to improve goodness-of-fit. However, the biological significance of overestimating lesion density at temperatures of 27 to $30^{\circ} \mathrm{C}$ may be minimal if periods of high $\mathrm{RH}$ at these temperatures are rare.

The observed response to temperature in this study differs from that reported by Jensen and Boyle $(23,24)$, who did not report a unimodal response to temperature. In the Jensen and Boyle nomogram, fewer wetness hours are required for a favorable $T / \mathrm{RH}$ index at temperatures from 22 to $27^{\circ} \mathrm{C}$ than from 18 to $22^{\circ} \mathrm{C}$. Results presented herein indicate the opposite. At $27^{\circ} \mathrm{C}$, one lesion per leaf was expected following 32, 38, and $46 \mathrm{~h}$ of wetness for 'Spanco', 'Florunner', and 'Okrun', respectively. At $21^{\circ} \mathrm{C}$, one lesion per leaf was expected following 28,32 , and $38 \mathrm{~h}$ of wetness for the respective cultivars. Similar discrepancies were found between the Jensen and Boyle model and observed infection under controlled conditions for late leaf spot (41). These results help explain why needed sprays sometimes were not made according to the PSC advisory program during its evaluation in Oklahoma (47). In years when the PSC program performed poorly, disease increase often followed extended wetness periods when temperature was below that required for a favorable spray advisory. In the VA advisory program (10), temperature over the range of 16 to $32^{\circ} \mathrm{C}$ is considered equally favorable for infection. Disease control with the VA program was superior to the PSC program in Oklahoma (47). However, it may be possible to improve the performance and efficiency of this advisory program by accounting for unimodal response to temperature.

Lesion density increased with wetness duration in a sigmoidal fashion. Others working with late leaf spot have reported abrupt (41) or exponential (9) responses to wetness duration. The interaction of wetness with temperature and cultivar also impacted disease development. Fewer hours of wetness were required to achieve a specific disease intensity as temperature approached an optimum. The observed interaction of cultivar and wetness duration was manifested by a longer wetness period required to achieve a specific level of disease for a partially resistant compared with a susceptible cultivar. These results support the proposed modification of wetness duration thresholds in the VA advisory program for cultivars that differ in disease reaction (10) and verify field observations that optimum thresholds differ for cultivars used in this study (47). Wetness durations that supported infection in this study were similar, but somewhat lower, than the spray thresholds identified in the field $(10,47)$.

Cultivars clearly differed in their reaction to early leaf spot. Reduced lesion density and lesion size are important components of partial resistance for early leaf spot and may help explain the delay in disease increase and AUDPC observed in the field with these runner cultivars in comparison to Spanish cultivars such as Spanco $(11,47)$. Previous reports conflict regarding differences in reaction to early leaf spot among runner and Spanish varieties. Sowell et al. (43) reported no difference between Spanish cv. Argentine and cv. Florunner in the field. Gobina et al. (20) reported fewer lesions per leaf and reduced sporulation in one of two trials each for cv. Florunner compared with the Spanish cvs. Tamnut 74 and Comet. In single ratings near harvest, Melouk and Banks (29) reported no differences in leaf spot incidence, sporulation, or defoliation between cv. Florunner and the Spanish cvs. Pronto, Comet, and Tamnut 74. Hassan and Beute (21) reported differences between cv. Florunner and Spanish cultivars such as Starr for some response criteria, but not for others.

Lesion density has not always been a reliable indicator of partial resistance to early leaf spot $(21,39,44)$. Differences in cultivar rankings between trials for this response variable have been attributed to environment (21) and inoculum density (33). Given the controlled inoculum densities used in this study, lesion density was stable across cultivars at each temperature, but did vary with wetness duration. For late leaf spot, lesion density was stable across a range of temperatures and wetness durations and accurately reflected genotype differences (41). In this study, there was no interaction of cultivar with temperature for lesion size or density with as previously reported for $C$. arachidicola (45).

Cultivar resistance has been characterized by variation in intrinsic, temporal rate of disease increase $(40,46)$ and variation in the upper limit of disease $(32,35)$. Results of this study tend to support the latter mechanism. Effects of resistance on the scale of response, the intrinsic temporal rate of increase, the intrinsic temporal rate of acceleration, and the intrinsic rate of change with temperature and optimum temperature were evaluated for early leaf spot of peanut. Resistance clearly had a large effect on the response scale: the level of disease was reduced with increasing resistance, but had no effect on temperature optima. Effects of resistance on the intrinsic temporal rate and on the intrinsic rate of change with respect to temperature were smaller and more variable. However, in the field, cultivars are exposed to multiple cycles of disease in contrast to the single cycle of infection in this study. Ultimately, the rate of disease increase over multiple cycles in the field is likely to be affected by reductions in lesion density, lesion size, and other components of partial resistance.

\section{ACKNOWLEDGMENTS}

Approved for publication by the director, Oklahoma Agricultural Experimental Station. This research was funded, in part, by Hatch project H2159 and the Samuel Roberts Noble Foundation. 


\section{LITERATURE CITED}

1. Abdou, Y. A.-M., Gregory, W. C., and Cooper, W. E. 1974. Sources and nature of resistance to Cercospora arachidicola Hori and Cercosporidium personatum (Berk. and Curtis) Deighton in Arachis species. Peanut Sci. 1:6-11.

2. Alderman, S. C., and Beute, M. K. 1986. Influence of temperature and moisture on germination and germ tube elongation of Cercospora arachidicola. Phytopathology 76:715-719.

3. Alderman, S. C., and Beute, M. K. 1987. Influence of temperature, lesion water potential, and cyclic wet-dry periods on sporulation of Cercospora arachidicola on peanut. Phytopathology 77:960-963.

4. Arauz, L. F., and Sutton, T. B. 1989. Influence of temperature and moisture on germination of ascospores and conidia of Botryosphaeria obtusa. Phytopathology 79:667-674.

5. Arauz, L. F., and Sutton, T. B. 1989. Temperature and wetness duration requirements for apple infection by Botryosphaeria obtusa. Phytopathology 79:440-444.

6. Arny, C. J., and Rowe, R. C. 1991. Effects of temperature and duration of surface wetness on spore production and infection of cucumbers by Didymella bryoniae. Phytopathology 81:206-209.

7. Bailey, J. E., Johnson, G. L., and Toth, S. J. 1994. Evolution of a weather-based peanut leaf spot spray advisory in North Carolina. Plant Dis. 78:530-535.

8. Boote, K. J. 1982. Growth stages of peanut (Arachis hypogaea L.). Peanut Sci. 9:35-39.

9. Butler, D. R., Wadia, K. D. R., and Hadhav, D. R. 1994. Effects of leaf wetness and temperature on late leaf spot infection of groundnut. Plant Pathol. 43:112-120.

10. Cu, R. M., and Phipps, P. M. 1993. Development of a pathogen growth response model for the Virginia peanut leaf spot advisory program. Phytopathology 83:195-201.

11. Damicone, J. P., Jackson, K. E., Sholar, J. R., and Gregory, M. S. 1994. Evaluation of a spray advisory for management of early leaf spot of peanut in Oklahoma. Peanut Sci. 21:115-121.

12. Dhingra, O. D., and Sinclair, J. B. 1985. Basic Plant Pathology Methods. CRC Press, Boca Raton, FL.

13. Duthie, J. A. 1997. Models of the response of foliar parasites to the combined effects of temperature and duration of wetness. Phytopathology 87:1088-1095.

14. Duthie, J. A., and Damicone, J. P. 1995. A mechanistic model of the response of a foliar parasite to combined effects of temperature and duration of leaf wetness. (Abstr.) Phytopathology 85:1158.

15. Duthie, J. A., and Damicone, J. P. 1996. A mechanistic model of combined effects of temperature and duration of wetness on intensity of a foliar disease. (Abstr.) Phytopathology 86(suppl.):S4.

16. Eisensmith, S. P., and Jones, A. L. 1981. A model for detecting infection periods of Coccomyces hiemalis on sour cherry. Phytopathology 71:728-732.

17. Elliot, V. J. 1988. Response models for conidiospore germination and germ tube elongation of Mycosphaerella fragariae as influenced by temperature and moisture. Phytopathology 78:645-650.

18. Evans, C. K., Hunger, R. M., and Siegerist, W. C. 1996. Inoculum density and infection efficiency of conidia and conidiophores of isolates of Pyrenophora tritici-repentis. Plant Dis. 80:505-512.

19. Evans, K. J., Nyquist, W. E., and Latin, R. X. 1992. A model based on temperature and leaf wetness duration for establishment of Alternaria leaf blight of muskmelon. Phytopathology 82:890-895.

20. Gobina, S. M., Melouk, H. A., and Banks, D. J. 1983. Sporulation of Cercospora arachidicola as a criterion for screening peanut genotypes for leaf spot resistance. Phytopathology 73:556-558.

21. Hassan, H. N., and Beute, M. K. 1977. Evaluation of resistance to Cercospora leafspot in peanut germplasm potentially useful in a breeding program. Peanut. Sci. 4:78-83.

22. Hau, B., Eisensmith, S. P., and Kranz, J. 1985. Construction of temporal models. Pages 31-65 in: Advances in Plant Pathology, Vol. 3. Mathematical Modelling of Crop Disease. C. A. Gilligan, ed. Academic Press, New York.

23. Jensen, R. E., and Boyle, L. W. 1965. The effect of temperature, relative humidity and precipitation on peanut leafspot. Plant Dis. Rep. 49:975-978.

24. Jensen, R. E., and Boyle, L. W. 1966. A technique for forecasting leafspot on peanuts. Plant Dis. Rep. 50:810-814.

25. Johnson, C. S., and Beute, M. K. 1986. The role of partial resistance in the management of Cercospora leaf spot of peanut in North Carolina. Phytopathology 76:468-472.

26. Johnson, C. S., Beute, M. K., and Ricker, M. D. 1986. Relationship between components of resistance and disease progress of early leaf spot on Virginia-type peanut. Phytopathology 76:495-499.

27. Madden, L. V., and Campbell, C. L. 1990. Nonlinear disease progress curves. Pages 181-229 in: Epidemics of Plant Diseases: Mathematical Analysis and Modeling, 2nd ed. J. Kranz, ed. Springer-Verlag, Berlin.

28. Matyac, C. A., and Bailey, J. E. 1988. Modification of the peanut leaf spot advisory for use on genotypes with partial resistance. Phytopathology 78:640-644.

29. Melouk, H. A., and Banks, D. J. 1978. A method of screening peanut genotypes for resistance to Cercospora leafspot. Peanut Sci. 5:112-114.

30. Melouk, H. A., Banks, D. J., and Fanous, M. A. 1984. Assessment of resistance to Cercospora arachidicola in peanut genotypes in field plots. Plant Dis. 68:395-397.

31. Monroe, J. S., Santini, J. B., and Latin, R. 1997. A model defining the relationship between temperature and leaf wetness duration, and infection of watermelon by Colletotrichum orbiculare. Plant Dis. 81:739-742.

32. Neher, D. A., and Campbell, C. L. 1992. Underestimation of disease progress rates with the logistic, monomolecular, and Gompertz models when maximum disease intensity is less than 100 percent. Phytopathology 82:811-814.

33. Nevill, D. J. 1981. Components of resistance to Cercospora arachidicola and Cercosporidium personatum in groundnuts. Ann. Appl. Biol. 99:77-86.

34. Oso, B. A. 1972. Conidial germination in Cercospora arachidicola Hori. Trans. Br. Mycol. Soc. 59:169-172.

35. Park, E. W., and Lim, S. M. 1985. Empirical estimation of the asymptotes of disease progress curves and the use of the Richards generalized rate parameters for describing disease progress. Phytopathology 75:786-791.

36. Parlevliet, J. E. 1979. Components of resistance that reduce the rate of epidemic development. Annu. Rev. Phytopathol. 17:203-222.

37. Parvin, Jr., D. W., Smith, D. H., and Crosby, F. L. 1974. Development and evaluation of a computerized forecasting method for Cercospora leafspot of peanuts. Phytopathology 64:385-388.

38. Phipps, P. M., and Powell, N. L. 1984. Evaluation of criteria for the utilization of peanut leafspot advisories in Virginia. Phytopathology 74: 1189-1193.

39. Ricker, M. D., Beute, M. K., and Campbell, C. L. 1985. Components of resistance in peanut to Cercospora arachidicola. Plant Dis. 69:1059-1064.

40. Shaner, G., and Finney, R. E. 1977. The effect of nitrogen fertilization on the expression of slow-mildewing resistance in Knox wheat. Phytopathology 67:1051-1056.

41. Shew, B. B., Beute, M. K., and Wynne, J. C. 1988. Effects of temperature and relative humidity on expression of resistance to Cercosporidium personatum in peanut. Phytopathology 78:493-498.

42. Smith, D. H., and Littrell, R. H. 1980. Management of peanut foliar diseases with fungicides. Plant Dis. 64:356-361.

43. Sowell, Jr., G., Smith, D. H., and Hammons, R. O. 1976. Resistance of peanut plant introductions to Cercospora arachidicola. Plant Dis. Rep. 60:494-498

44. Waliyar, F., McDonald, D., Subba Rao, P. V., and Reddy, P. M. 1993. Components of resistance to an Indian source of Cercospora arachidicola in selected peanut lines. Peanut Sci. 20:93-96.

45. Waliyar, F., Shew, B. B., Stalker, H. T., Isleib, T. G., Sidahmed, R., and Beute, M. K. 1994. Effect of temperature on stability of components of resistance to Cercospora arachidicola in peanut. Phytopathology 84: 1037-1043.

46. Wilcoxson, R. D., Skovmand, B., and Atif, A. H. 1975. Evaluation of wheat cultivars for ability to retard development of stem rust. Ann. Appl. Biol. 80:275-281.

47. Wu, L., Damicone, J. P., and Jackson, K. E. 1996. Comparison of weather-based advisory programs for managing early leaf spot on runner and Spanish peanut cultivars. Plant Dis. 80:640-645. 